\title{
Differential Regulation of Hippocampal Glucocorticoid Receptors mRNA and Fast Feedback: Relevance to Post-Traumatic Stress Disorder
}

\author{
I. Liberzon*†, J. F. López*, S. B. Flagel*, D. M. Vázquez* and E. A. Young* \\ *Mental Health Research Institute, Department of Psychiatry, University of Michigan, Ann Arbor, MI, USA. \\ $\nmid$ Psychiatry Service, Veteran's Administration Medical Center, Ann Arbor, MI, USA.
}

Key words: GR, MR, mRNA, post-traumatic stress disorder.

\begin{abstract}
Hippocampal glucocorticoid receptors (GR and MR) play an important role in glucocorticoid negative feedback. Abnormalities in negative feedback are found in depression and in posttraumatic stress disorder (PTSD), suggesting that GR and MR might be involved in the pathophysiology of these disorders. Enhanced negative feedback, the PTSD-specific neuroendocrine abnormality, can be induced in animals using a single prolonged stress (SPS) paradigm (a number of different stressors in one prolonged session, 'no stress' interval and a testing session one week later). In the current study, we examined hippocampal GR and MR mRNA distribution in the same animals that exhibited altered negative feedback following the SPS. Seven groups of adult SpragueDawley male rats (seven animals each) were used in two studies, comparing unstressed controls to acutely stressed animals (SPS: $24 \mathrm{~h}$ group), SPS animals (seven and 14 days), and SPS + chronic stress animals. GR and MR mRNA distribution across hippocampal subfields was studied using insitu hybridization with ${ }^{35} \mathrm{~S}$-labelled cRNA probes. Acute stress produced down-regulation of GR and MR mRNA across all hippocampal subfields. Seven days later (SPS-7 group), there was a differential recovery, with GR mRNA reaching higher than the prestress levels, and MR mRNA remaining downregulated. The same differential regulation was present in the 14-day group. Chronically stressed animals that exhibited normal fast feedback also had normalization in their GR and MR mRNA levels. The MR/GR ratio was decreased only in animals that had enhanced fast feedback. These findings suggest that the increase in GR, in hippocampus is involved in the fast feedback hypersensitivity observed in the SPS animals, and might also underlie enhanced dexamethasone sensitivity found in PTSD. Since differential activation of GR and MR can modulate memory, behavioural responsivity, anxiety and fear, change in MR/GR ratio might also explain other PTSDrelated phenomena.
\end{abstract}

Hippocampal glucocorticoid receptors have been shown to play an important role in hypothalmic-pituitary-adrenal (HPA) axis regulation through their effects on glucocorticoid negative feedback (1-3). Both Type I (MR) and Type II (GR) glucocorticoid receptors are present (in abundance) in the hippocampus, and are differentially distributed across subfields. The respective roles of these receptors in negative feedback regulation is yet to be fully elucidated. Electrophysiologic and behavioural studies suggest that GR and MR might exert different, and even functionally antagon- istic, effects (4). On the other hand, their effects on HPA axis regulation appear to be synergistic $(5,6)$. Understanding of the specific roles of GR versus MR with respect to negative feedback regulation is clearly needed for a better understanding of the conditions associated with abnormal negative feedback.

Abnormalities in glucocorticoid negative feedback are among the most robust neurobiological findings reported in psychiatric disorders. Decreased negative feedback is found in major depression (7) and enhanced negative feedback has

Correspondence to: Israel Liberzon, MD, Mental Health Research Institute, Department of Psychiatry, University of Michigan, 205 Zina Pitcher Place, Ann Arbor, MI 48109-0720, USA. 
12 Hippocampal GR and MR and negative feedback

been found by Yehuda et al. (8) in post-traumatic stress disorder (PTSD), suggesting that alterations of negative feedback in either direction can occur. An increase in lymphocyte glucocorticoid receptors was also found in patients with PTSD, and postulated to occur in the hippocampus (9), conceptually linking abnormal negative feedback with glucocorticoid receptor changes. No data is currently available regarding hippocampal glucocorticoid receptors in psychiatric disorders. Animal models of chronic stress have generally demonstrated decreased hippocampal glucocorticoid receptors $(10-12)$ which differs from the change that was hypothesized to occure in PTSD.

The relevance of hippocampal GR and MR receptors to psychiatric disorders is not limited to their effects on glucocorticoid negative feedback. Activation or blocade of these receptors can modulate systems associated with memory, behavioural responsivity, anxiety and fear. Overall MR activity is thought to stabilize hippocampal function, decreasing CA1 firing and enhancing hippocampal control over the HPA axis $(6,13)$. Thus, animals with increased MR capacity have decreased neuroendocrine responsivity to stress (14). Behaviourally, MR antagonism appears anxiolytic (decreasing fear motivated immobility in elevated plus-maze (15)), and the blockade of both GR and MR appears anxiogenic, producing an increase in acoustic startle response (16). DeKloet et al. (4) formulated the 'Corticosteroid receptor balance' hypothesis, based on these findings, and suggested that MR deficiency will lead to limbic disinhibition (13). Changes in hippocampal GR and MR therefore could mediate both the behavioural/emotional changes and the negative feedback abnormalities reported in psychiatric disorders.

Studies of animals exposed to stress have demonstrated that differential regulation of negative feedback is possible, depending on the particular variables of stress exposure (17-19). We had demonstrated that a specific stress paradigm (single prolonged stress followed by a 1-week 'untouched' interval: SPS) induces hypersensitive glucocorticoid fast feedback, and proposed that it is an animal model of PTSDspecific neuroendocrine abnormality (19). To determine the link between hypersensitive fast feedback and glucocorticoid receptors in the hippocampus, we examined hippocampal glucocorticoid receptors in animals with altered fast feedback. We examined GR and MR mRNA distribution using in-situ hybridization in the hippocampal subfields, in the same animals that exhibited enhanced fast feedback.

\section{Results}

All the animals in SPS-24 h, SPS, SPS-7, and SPS-14 groups (in both studies) received a similar single prolonged stress session. The results are presented therefore as a function of the time elapsed from this single stress session. A single prolonged stress induced down-regulation of both GR and MR mRNA levels $24 \mathrm{~h}$ later across all hippocampal subfields (see Figs 1 and 2). (Two-way ANOVA with groups and regions (subfields) as independent factors, $F(3,94)=30.9$, $\mathrm{P}<0.001$ for $\mathrm{GR}$ mRNA, and $\mathrm{F}(3,96)=9.3, \mathrm{P}<0.001$, for MR mRNA). There was also an expected, significant effect of regions $(\mathrm{F}(3,94)=257, \mathrm{P}<0.001$ and $\mathrm{F}(3,96)=9.8$, $\mathrm{P}<0.001$ for $\mathrm{GR}$ and $\mathrm{MR}$, respectively), but no significant

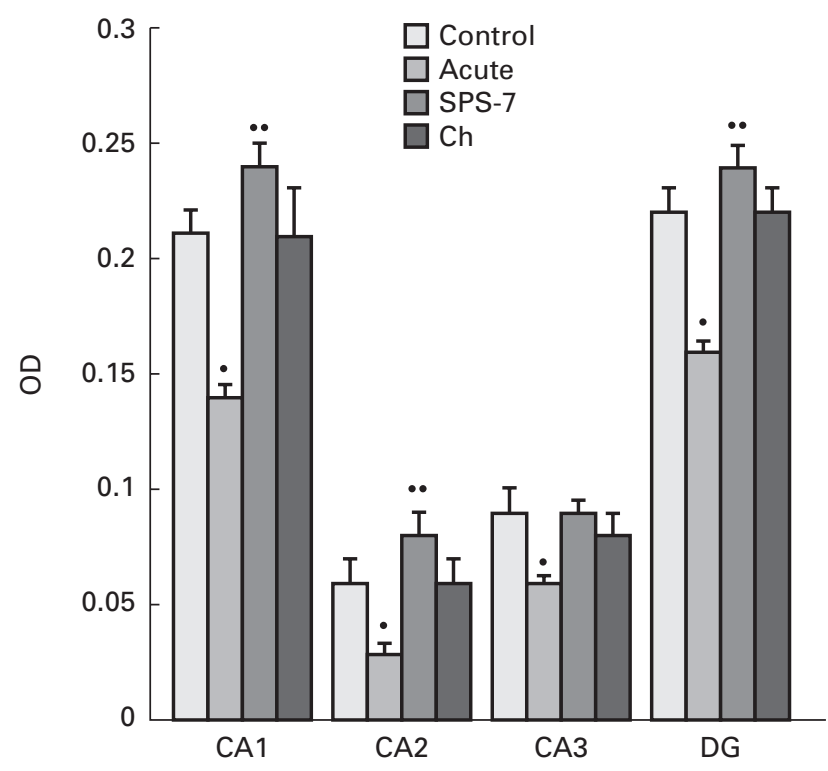

FIG. 1. GR mRNA changes within hippocampal subfields, 24 hours and 7 days following the SPS, as compared to controls and chronically stressed animals (Study I). Both SPS group are significantly different from the controls and chronically stressed animals (post-hoc Scheffe $\mathrm{P}<0.05$ ), and from each other. (SPS-24h group is lower-() and the SPS-7 is higher $-(\infty \infty)$ then controls $)$.

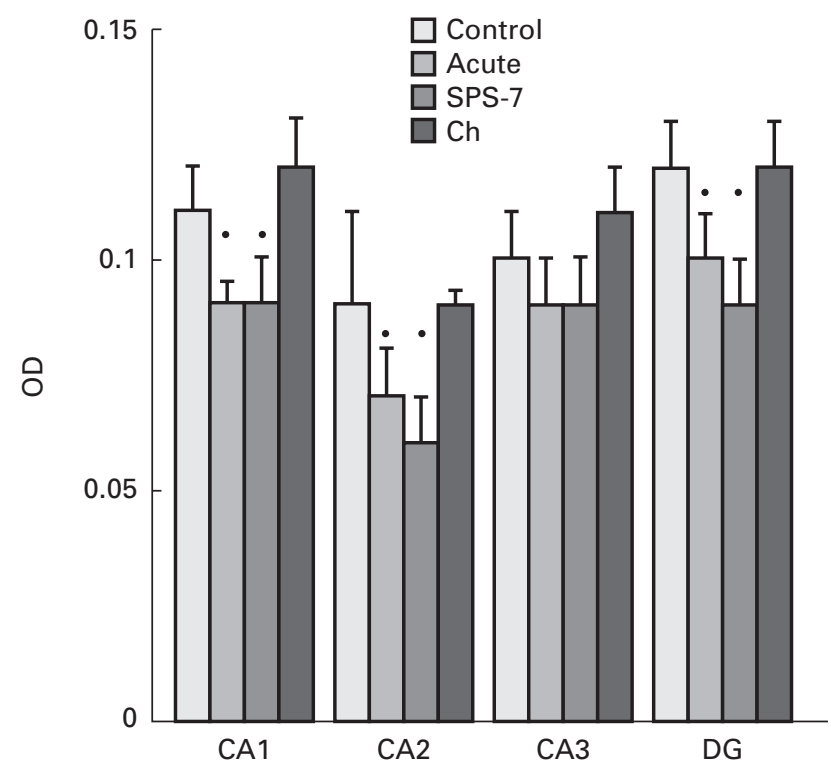

FIG. 2. MR mRNA changes within hippocampal subfields, 24 hours and 7 days following the SPS, compared to controls and chronically stressed animals (Study I). Both SPS groups are significantly lower then the controls and chronically stressed animals ( post-hoc Scheffe () $-\mathrm{P}<0.05$ ), and not different from each other.

interaction effects for both GR and MR mRNA. Post-hoc testing in each of the subfields separetly (Scheffe), confirmed significant differences between Control and SPS-24 h groups.

Seven days later (SPS-7 group) there was a recovery of GR mRNA levels across all the hippocampal subfields (Fig. 1). Moreover, the GR mRNA increased to significantly 


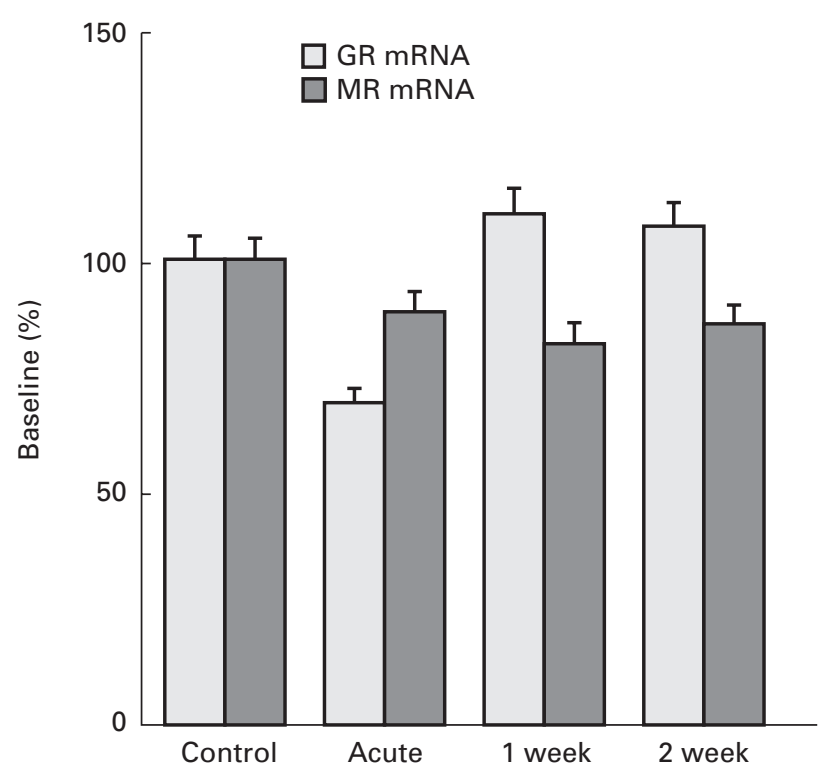

FIG. 3. GR and MR mRNA changes across the whole hippocampus, 7 and 14 days following the SPS (Study I and Study II combined.). For the purpose of illustration the data are presented as a percent of a 'baseline'-normalized to the respective non-stressed controls within each study.

higher than the prestress levels, across the hippocampal subfields. (SPS-7 group significantly higher then SPS-24 h and Control groups: $\mathrm{F}(3,94)=30.9, \mathrm{P}<0.001$, Scheffe $\mathrm{P}<0.001$ in both comparisons). However, the MR mRNA level was still down-regulated after 7 days (SPS-7 group), remaining lower than the Control group $(F(3,96)=9.3$ $\mathrm{P}<0.001$, Scheffe $\mathrm{P}<0.01)$ and not different than the SPS-24 h group (Scheffe $\mathrm{P}=0.85$ ), see Fig. 2. Interestingly, in chronically stressed animals (Chronic group), there was a full recovery of MR mRNA and also a return to the baseline of GR mRNA (Chronic group not different from Controls across all hippocampal subfields: Scheffe, $P=1.0$ for $G R$ and $\mathrm{P}=0.7$ for $\mathrm{MR}$ ). The differential regulation of $\mathrm{GR}$ and $\mathrm{MR}$ mRNA (with GR mRNA recovering and MR mRNA remaining down-regulated), 7 days after the single prolonged stress, was independently replicated in Study II.

Fourteen days after the single prolonged stress (SPS-14 group), there was an increase in GR mRNA levels above the prestress levels across hippocampal subfields (two-ways ANOVA F $(2,68=9.5, \mathrm{P}<0.001 ;$ Scheffe $\mathrm{P}<0.05$ for SPS-14 versus Controls; see Fig. 3 for summary). When the hippocampal subfields were examined separately, there was a significant GR mRNA elevation in the SPS-14 group in CA1 and DG (one-way ANOVAs with Scheffe $\mathrm{P}<0.05$. $\mathrm{f}=4.2$, d.f. $=2, P=0.03$, in $\mathrm{CA} 1, \mathrm{f}=4.9$, d.f. $=2, \mathrm{P}=0.02$ in $\mathrm{DG}$ ), and no significant difference in CA2 and CA3 subfields. MR mRNA levels remained down-regulated after 14 days across all the subfields, (two-way ANOVA F $(2,68)=14.6 \mathrm{P}<0.001$, Scheffe $\mathrm{P}<0.001)$ and not different from the SPS-7 group levels (Scheffe $P=0.6$ ). The significant decrease was contributed mostly by the decreases in DG (one-way ANOVA, $\mathrm{f}=$ 6.2, d.f. $=2 \mathrm{P}=0.009$, Scheffe $\mathrm{P}<0.05$ ) and $\mathrm{CA} 2$ ( $\mathrm{f}=3.6$, d.f. $=2 \mathrm{P}=0.04$, Scheffe $\mathrm{P}<0.05)$.
We have also examined MR/GR ratios across hippocampal subfields in both studies (Fig. 4). There was a increase in $\mathrm{MR} / \mathrm{GR}$ ratio in the SPS-24 h group (two-ways ANOVA, effect of group $\mathrm{F}(2,64)=19.7 \mathrm{P}<0.001$, Scheffe $\mathrm{P}<0.01)$, and a significant decrease in MR/GR ratio in the SPS groups after 7 and 14 days, compared to respective controls (two-way ANOVA effect of group $\mathrm{F}(2,64)=19.7 \mathrm{P}<0.001$, Scheffe $\mathrm{P}<0.05$ for 7 days, and $\mathrm{F}(2,68)=7.8 \mathrm{P}<0.002$, Scheffe $\mathrm{P}<0.01$ for 14 days). There was no difference in MR/GR ratio between the 7 and 14 days groups. When hippocampal subfields were examined separately, the significant decrease in the MR/GR ratio was contributed mostly to changes in DG and CA1 and CA2 subfields. The increase in MR/GR ratio in the SPS-24 h group appeared homogeneously across all the subfields.

\section{Discussion}

A single prolong stress produced differential regulation of GR and MR mRNA in the hippocampus. Transient downregulation, with subsequent up-regulation above the control levels, of GR mRNA, and sustained down-regulation of MR mRNA occurred, inducing a 'shift' toward lower MR/GR mRNA ratio 7 days from the SPS session. This absolute increase in GR mRNA and a shift in MR/GR ratio was present for at least 1 additional week ( 2 weeks after the stress session), although both GR and MR mRNA level continued to increase. We have found an increased sensitivity to glucocorticoid fast feedback in the same animals that had this differential regulation of GR and MR mRNAs (19) or a 'shift' in MR/GR ratio. Since hippocampal glucocorticoid receptors play a central role in glucocorticoid negative feedback regulation $(2,20)$, we are proposing that the increase

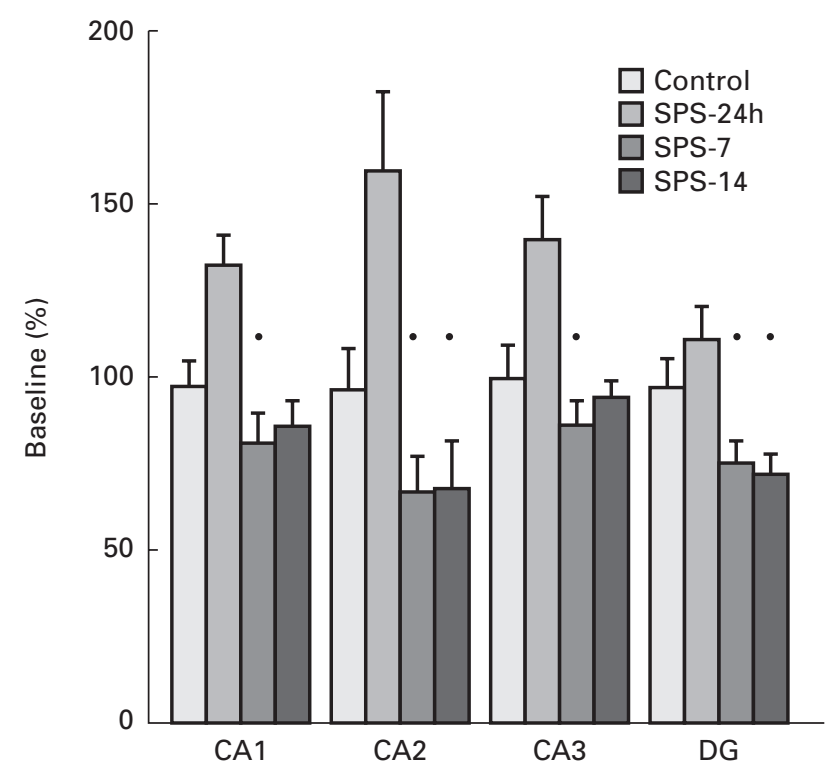

FIG. 4. MR/GR ratio changes within hippocampal subfields, 24 hours, 7 and 14 days following the SPS, compared to controls (Study I and Study II combined.). SPS-7 and SPS-14 groups are significantly lower then the controls-(), while SPS-24h group is significantly higher (posthoc Scheffe; $\mathrm{P}<0.05$ ). 
in GR in hippocampus is involved in fast feedback hypersensitivity observed in the SPS animals. This suggests that GR activity is a dominant factor in the mediation hypersensitive fast feedback observed in these animals, since enhanced fast feedback was observed even in presence of lower MR mRNA levels. Similarly, enhanced ACTH response to stress in presence of low MR and unchanged GR levels was reported by others (21). The decrease in MR suggest that lower MR in the presence of higher GR does not alter the increase sensitivity to negative feedback, or alternatively, that MR plays less prominent role in the fast feedback regulation. In studies, examining the effects of a single stress on hippocampal glucocorticoid receptors, upregulation of both GR and MR binding was found 2 weeks after a single inescapable shock session (22). Interestingly, the reported data also suggest differential regulation of GR and MR and decreased MR/GR ratio in this study, with GR up-regulation to $129 \%$ of control level and MR up-regulation to $114 \%$. The authors speculate that these changes might be associated with changes in negative feedback, however, negative feedback was not assessed in their study. In the present study we have replicated up-regulation of GR as assessed by steady state mRNA levels at 2 weeks.

Furthermore, we have found that animals that have been continuously stressed for 1 week after the SPS, had restored both their MR and GR mRNA to the normal (pre-stress) levels. This suggests that repeated stress lends to a compensatory increase in MR mRNA and return of GR mRNA to prestress levels, with a 'restoration' in MR/GR ratio. The same chronically stressed animals exhibited normal (not hypersensitive) glucocorticoid fast feedback (19). This further supports the hypothesis that an increase in GR plays a prominent role in fast feedback hypersensitivity.

While the link between the increase in GR function and the enhanced fast feedback appears self evident, the role of $\mathrm{MR} / \mathrm{GR}$ ratio in behavioural function, requires further consideration. HPA axis studies suggest that GR and MR might act in concert (6), however, both behavioural and electrophysiological studies suggest that GR and MR might act in antagonistic manner in these systems. Behavioural reactivity and extinction of avoidant conditioning are impaired in adrenalectomized animals, restored with low dose corticosterone replacement (MR activation) and impaired with the high dose replacement (both GR and MR activation) (23). DeKloet and Joels reported similar differential effects of predominantly MR versus GR and MR occupation on ion permeability (24), and Palvides et al. reported differential effect on long-term potentiation (25). Antagonistic effects of GR and MR could explain the importance of MR/GR ratio in these systems, since the change in $\mathrm{MR} / \mathrm{GR}$ ratio might potentially alter physiological output, in the presence of unaltered glucocorticoid levels. Based on this evidence, DeKloet and colleagues proposed the 'MR/GR ratio' hypothesis (4), and the present findings may be relevant for behavioural syndrome seen in PTSD.

A single exposure to a stressor has been shown to induce behavioural and neurobiological changes in other studies. Persistent electrophysiological changes and enhanced corticosterone response following brief stress exposure were reported by Antelman $(26,27)$. Van Dijken et al. reported increased behavioural reactivity (locomotion and defecation in the open field) 2 weeks after single session of unpredictable shock (28), that were reversible by the anxiolytic agents (29). Authors suggested that long-lasting changes following a brief stress session in animals are likely related to the phenomenon of human anxiety (28). Van Dijken et al. also found increased colocalization of CRF and AVP neurones in the median eminence in animals exposed to a single stress session. Since AVP expression in PVN is sensitive to MR regulation, it is possible that lowered MR activity is a contributing factor in this increased colocalization.

The presence of long-lasting effects after a single stress session might appear surprising, especially when chronically stressed animals did not show similar effects. However, if one postulates the existence of both sensitization and habituation mechanisms in the stress response (30), the differential effects of single and chronic stress can be explained (enhanced negative feedback can be seen as an expression of a sensitized inhibitory component of HPA axis). Pitman et al. (30) suggested that examination of the HPA response to a single probe is a possible model to study this process and argued that sensitization requires prolonged time course. In turn, if habituation (or a compensatory response) is mainly a function of repetition of a stressful stimulus, a single session and chronic stress might trigger predominantly different processes. If stressor intensity is another defining factor in the development of sensitization (30), the SPS paradigm will 'favour' the sensitization process, due to both high intensity and the prolonged duration of the stress session, and the 'built in' time interval of 7 days after the stress session that allows sensitization to develop.

It is important to point out that the changes we have found in the GR and MR mRNA levels do not necessarily imply similar regulation on the level of the receptor protein. Since the traditional binding studies are unable to distinguish receptor downregulation from the receptors occupied by endogenous ligand (31), future studies will need to address this question using Western blot procedures. Cortisol pretreatment and restraint which were applied to our animals in the first study $30 \mathrm{~min}$ before they were killed, are possible confounds in measuring MR and GR mRNA levels. Since a longer time is usually necessary for change in mRNA steady state levels, and since our second study, which did not have negative feedback assessment (cortisol injection) independently replicated the first study results, it is unlikely that the assessment of negative feedback had a significant effect on GR and MR mRNA. It is unlikely that the changes in GR and MR mRNA simply reflect chronically elevated levels of circulating glucocorticoids, since in our SPS-24 h (Acute) group we have observed cortisol and ACTH returning to normal within $24 \mathrm{~h}$ (19) while both GR and MR remained down-regulated. One might also wonder whether chronically stressed animals would have an altered $\mathrm{MR} / \mathrm{GR}$ ratio if they were assessed 7 days instead of $24 \mathrm{~h}$ after their last stress. While it is possible, it should be noted that the GR and MR mRNA in the chronic stress group have already returned to the normal levels and are not down-regulated (as seen in the SPS-24 h stress group). Future studies are needed to obtained a definitive answer to this question.

We observed a relatively homogeneous change across all 
hippocampal subfields in our animals, for both GR and MR mRNA, $24 \mathrm{~h}$ and 7 days after the SPS. However, 2 weeks after the SPS, significant up-regulation of GR mRNA was seen mostly in CA1 and DG regions, while MR mRNA down-regulation was mostly contributed by the changes in CA2 and DG. While all the changes together create a similar shift toward lower MR/GR ratio across CA1, CA2, and DG, the GR and MR regulation across various subfields might differ, and this could have functional significance in negative feedback regulation.

Both the role of GR and MR in regulation of negative feedback, and the ability of SPS paradigm to induce change in both and to enhance negative feedback, carries great relevance to the study of PTSD. As mentioned earlier, hypersensitive glucocorticoid negative feedback (8), and higher lymphocyte glucocorticoid receptor numbers (9) have been demonstrated in PTSD. Enhanced dexamethasone negative feedback has been demonstrated in PTSD patients, and we have demonstrated enhanced fast feedback in the SPS model. If similarly to SPS animals, there is an increase in GR function in PTSD patients, this could account for their enhanced suppression to dexamethasone. Additional experiments examining other types of negative feedback, and other neurobiological systems are needed however, to further validate the utility of SPS paradigm as animal model for PTSD. Interestingly, morphological changes in the hippocampi of PTSD patients (smaller hippocampi) have also been reported in MRI studies $(32,33)$, but it is not known whether they predate, or result from, the development of PTSD. If the GR and MR are important for negative feedback, and the hippocampal changes in PTSD are also 'selective' (affecting subfields richer in MR then GR for example), this could explain both an overall lower hippocampal volume and the intact negative feedback. Alternatively, it has been suggested that MR carry a neuro-protective function in the hippocampus (34). Abnormally low or down-regulated hippocampal MR in traumatized PTSD patients may in turn predispose them to subsequent larger tissue loss. On the behavioural level, increased MR function is implicated in decreased anxiety/fear related behaviours in animals (14). If lower MR function, is associated with the increased anxiety/fear responses, then a decrease in hippocampal MR in PTSD could be responsible for the specific clinical picture including increased startle response, enhanced autonomic reactivity, hypervigilance and increased anxiety, found in this disorder. Finally, one highly debated questions in the PTSD arena is whether HPA findings are the results of stress and trauma, or they predate and possibly predispose individual to the development of PTSD. Our findings suggest that at least changes in GR (and MR) and in negative feedback can be induced using the SPS paradigm in an animal model.

\section{Materials and methods}

Animals

Adult Sprague-Dawley male rats weighing $\approx 250 \mathrm{~g}$ were obtained from the Reproductive Sciences Program colony, University of Michigan (MI, USA). Animals were housed in groups of three under a $12 \mathrm{~h}$ light-dark cycle. Food and water were available ad libitum. Following an adaptation period of 5-6 days, experimental procedures were undertaken.

Procedure

\section{Study I}

Twenty-eight animals were divided into four groups: 1) controls $(\mathrm{Cl}) ; 2$ ) single prolonged stress (SPS);3) acute stress (SPS-24 h); and 4) chronic non-abituating stress. Control animals remained in their home cages with no handling for 7 days and were killed at the same time as the stressed groups. All three stressed groups of animals had a similar single prolonged stress procedure on the first day. It included a continued prolonged stress session followed by a 7 day 'undisturbed' period. The single session of prolonged stress consisted of: restraint for $2 \mathrm{~h}$, followed by forced swim for $20 \mathrm{~min}\left(24^{\circ} \mathrm{C}\right)$, followed by ether anaesthesia. The SPS- $24 \mathrm{~h}$ stress group was killed $24 \mathrm{~h}$ after the termination of this procedure. The SPS group remained untouched in their home cages and was killed 7 days later. The chronic group was exposed to four different stressors (one or two daily) on a variable schedule for 7 days (see Table 1) and killed $24 \mathrm{~h}$ after the last stressor to eliminate the confounding effects of acute stress. All the animals had subcuteneous cortisol (30 $\mu \mathrm{g} / 100 \mathrm{gr}$ b.w.) injection, within $30 \mathrm{~min}$ of death, to assess their glucocorticoid fast feedback (neuroendocrine data reported elsewhere). The protocol was approved by the Committee for Animal Use, University of Michigan.

\section{Study II}

In order to replicate Study I findings, to examine the effect of SPS after 2 weeks, and to control for possible confounding effects of negative feedback assessment, we studied three groups of animals: Controls, SPS-7 (7 days untouched) and SPS-14 (14 days untouched). The procedure was similar to Study I, with the exclusion of cortisol pretreatment and tail nicks before being killed.

TABle 1. Non-Habituating Stress Schedule.

\begin{tabular}{|c|c|c|c|}
\hline Day & Time & First stressor & Second stressor (time) \\
\hline Day I & $2 \mathrm{pm}$ & forced swim, $20 \mathrm{~min}$ at $28^{\circ} \mathrm{C}$ & \\
\hline Day II & $12 \mathrm{pm}$ & restraint $3 \mathrm{~h}$ & \\
\hline Day III & $10 \mathrm{am}$ & ether anaesthesia & cold $4 \mathrm{~h}$ at $4{ }^{\circ} \mathrm{C}(2 \mathrm{pm})$ \\
\hline Day IV & 9 am & forced swim, $20 \mathrm{~min}$ at $24^{\circ} \mathrm{C}$ & restraint $2 \mathrm{~h}(1 \mathrm{pm})$ \\
\hline Day V & $8 \mathrm{am}$ & cold exposure, $4 \mathrm{~h}$ at $4^{\circ} \mathrm{C}$ & ether anaesthesia $(3 \mathrm{pm})$ \\
\hline Day VI & $2 \mathrm{am}$ & restraint $4 \mathrm{~h}$ & \\
\hline Day VII & $10 \mathrm{am}$ & forced swim, $20 \mathrm{~min}$ at $24^{\circ} \mathrm{C}$ & cold, $4 \mathrm{~h}$ at $4{ }^{\circ} \mathrm{C}(2 \mathrm{pm})$ \\
\hline
\end{tabular}




\section{Tissue samples and assays}

Following death, brains were immediately removed, frozen in isopentane $\left(-30^{\circ} \mathrm{C}\right)$ and cryostat sectioned $(15 \mu \mathrm{m})$ on polylysine coated slides. Sections were stored at $-80^{\circ} \mathrm{C}$ and studied within 1 month of death. GR mRNA was visualized using a cRNA probe synthesized from a $456 \mathrm{bp}$ fragment of GR cDNA (provided by Keith Yamamoto) subcloned into the XbaI-EcoRI site of pGEM 4 and directed against the protein binding region and the $3^{\prime}$ untranslated region of the GR mRNA. The MR cRNA probe was synthesized from a $347 \mathrm{bp}$ PstI-EcoRI fragment of MR cDNA (35) ligated into pGEM 3 and directed against the $3^{\prime}$ untranslated region of the MR mRNA. The specificity of these GR and MR riboprobes has been previously confirmed that the riboprobes were produced using either SP6 or T7 transcription systems in a standard labelling reaction mixture consisting of: $1 \mathrm{mg}$ linearized plasmid, 5X SP6 transcription buffer, $125 \mu \mathrm{Ci}{ }^{35} \mathrm{~S}$ UTP, $150 \mathrm{~mm}$ NTP's, $12.5 \mathrm{~mm}$ dithiothreitol, $20 \mathrm{U}$ RNAse inhibitor and $6 \mathrm{U}$ of the appropriate polymerase. The reaction was incubated at $37^{\circ} \mathrm{C}$ for $90 \mathrm{~min}$, labelled probe being separated from free nucleotides over a Sephadex G50-50 column.

\section{In-situ hybridization}

In-situ hybridization for GR and MR mRNA was performed using previously reported methods (36). Sections were removed from storage at $-80{ }^{\circ} \mathrm{C}$ and placed directly into $4 \%$ buffered paraformaldehyde at room temperature. After $60 \mathrm{~min}$, slides were rinsed in isotonic phosphate buffered saline $(10 \mathrm{~min})$ and treated with proteinase $\mathrm{K}(1 \mathrm{mg} / \mathrm{mL}$ in $100 \mathrm{~mm}$ Tris/HCL, pH 8.0) for $10 \mathrm{~min}$ at $37^{\circ} \mathrm{C}$. Subsequently, sections underwent successive washes in water $(1 \mathrm{~min}), 0.1 \mathrm{M}$ triethanolamine ( $\mathrm{pH} 8.0$, plus $0.25 \%$ acetic anhydride) for $10 \mathrm{~min}$ and $2 \times \mathrm{SSC}(0.3 \mathrm{mM} \mathrm{NaCl}, 0.03 \mathrm{~mm}$ sodium citrate, $\mathrm{pH}$ 7.2) for $5 \mathrm{~min}$. Sections were then dehydrated through graded alcohols and air dried.

Post-fixed sections were hybridized with $1.0 \times 10^{6}$ d.p.m. $\left[{ }^{35} \mathrm{~S}\right] \mathrm{UTP}-$ labelled riboprobes in hybridization buffer containing $75 \%$ formamide, $10 \%$ dextran sulphate, $3 \times \mathrm{SSC}$,

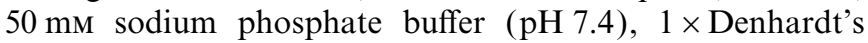
solution, $0.1 \mathrm{mg} / \mathrm{ml}$ yeast tRNA and $10 \mathrm{~mm}$ dithiothreitol in a total volume of $25 \mathrm{ml}$. The diluted probe was applied to sections on a glass coverslip which was sealed into place with rubber cement. Sections were hybridized overnight at $55^{\circ} \mathrm{C}$ in a humid environment. The rubber cement was removed after hybridization and sections were washed in $2 \times \mathrm{SSC}$ for $5 \mathrm{~min}$ and then treated with RNase A $(200 \mathrm{mg} / \mathrm{ml}$ in $10 \mathrm{mM}$ Tris/HCL, $\mathrm{pH} 8.0$, containing $0.5 \mathrm{M} \mathrm{NaCl}$ ) for $60 \mathrm{~min}$ at $37^{\circ} \mathrm{C}$. Subsequently, sections were washed in $2 \times \mathrm{SSC}$ for $5 \mathrm{~min}, 1 \times \mathrm{SSC}$ for $5 \mathrm{~min}, 0.5 \times \mathrm{SSC}$ for $60 \mathrm{~min}$ at hybridization temperature, $0.5 \times \mathrm{SSC}$ at room temperature for $5 \mathrm{~min}$ and then dehydrated in graded alcohols and air dried. For signal detection, sections were placed on Kodak XAR-5 $\mathrm{X}$-ray film and exposed for 2 days at room temperature.

\section{Microdensitometric analysis}

Autoradiograms generated from in-situ hybridization were analysed using an automated image analysis system (Dage camera, MAC II/IMAGE program, NIH, shareware). Anatomical regions of interest were interactively selected and mean optical density measurements for each region were determined from at least six coronal sections. Hippocampal subfields were determined with reference to Nissl-stained sections and the anatomical atlas of Paxinos and Watson (37). Non-specific labelling of $\left[{ }^{35} \mathrm{~S}\right]$ riboprobes was determined from an area of section exhibiting lack of hybridization signal. Statistical differences were determined by two-way anova (treatment groups and hippocampal subfields as independent factors) and post-hoc Scheffe.

\section{Acknowledgements}

The authors wish to acknowledge the support of MH 00427 and MH 45232 to EAY, and NARSAD/MIRA Young Investigator Award to JFL.

\section{Accepted 11 June 1998}

\section{References}

1 Herman JP, Patel PD, Akil H, Watson SJ. Localization and regulation of glucocorticoid and mineralocorticoid receptor messenger RNAs in the hippocampal formation of the rat. Mol Endocrinol 1989; 3: 1886-1894.

2 Sapolsky RM, Armanini MP, Packan DR, Sutton SW, Plotsky PM. Glucocorticoid feedback inhibition of adrenocorticotropic hormone secretagogue release. Relationship to corticosteroid receptor occupancy in various limbic sites. Neuroendocrinology 1990; 51: 328-336.

3 Cullinan WE, Herman JP, Watson SJ. Ventral subicular interaction with the hypothalamic paraventricular nucleus: evidence for a relay in the bed nucleus of the stria terminalis. J Comp Neurol 1993; 332: 1-20.

4 de Kloet ER, Oitzl MS, Joels M. Functional implications of brain corticosteroid receptor diversity. Cellular Mol Neurobiol 1993; 13: 433-455

5 Dallman MF, Levin N, Cascio CS, Akana SF, Jacobson L, Kuhn RW. Pharmacological evidence that the inhibition of diurnal adrenocorticotropin secretion by corticosteroids is mediated via type I corticosteronepreferring receptors. Endocrinology 1989; 124: 2844-2850.

6 Ratka A, Sutanto W, Bloemers M, de Kloet ER. On the role of brain mineralocorticoid (type I) and glucocorticoid (type II) receptors in neuroendocrine regulation. Neuroendocrinology 1989; 50: 117-123.

7 Young EA, Haskett RF, Murphy-Weinberg V, Watson SJ, Akil H. Loss of glucocorticoid fast feedback in depression. Arch Gen Psychiatry 1991; 48: 693-699.

8 Yehuda R, Southwick SM, Krystal JH, Bremner D, Charney DS, Mason JW. Enhanced suppression of cortisol following dexamethasone administration in posttraumatic stress disorder. Am J Psychiatry 1993; 150: $83-86$.

9 Yehuda R, Lowy MT, Southwick SM, Shaffer D, Giller E Jr. Lymphocyte glucocorticoid receptor number in posttraumatic stress disorder. Am J Psychiatry 1991; 148: 499-504.

10 Sapolsky RM, Krey LC, McEwen BS. Stress down-regulates corticosterone receptors in a site specific manner. Endocrinology 1984; 114: 287-292.

11 Sapolsky RM, Krey LC, McEwen BS. The neuroendocrinology of stress and aging: the glucocorticoid cascade hypothesis. Endocr Rev 1986; 7: 284-301.

12 De Kloet ER, Reul JM. Feedback action and tonic influence of corticosteroids on brain function: a concept arising from the heterogeneity of brain receptor systems. Psychoneuroendocrinology 1987; 12: 83-105.

13 De Kloet ER, Oitzl MS, Schobitz B. Cytokines and the brain corticosteroid receptor balance: relevance to pathophysiology of neuroendocrine-immune communication. Psychoneuroendocrinol 1994; 19: 121-134.

14 Oitzl MS, van Haarst AD, Sutanto W, de Kloet ER. Corticosterone, brain mineralocorticoid receptors (MRs) and the activity of the hypothalamic-pituitary-adrenal (HPA) axis: the Lewis rat as an example of increased central MR capacity and a hyporesponsive HPA axis. Psychoneuroendocrinology 1995; 20: 655-675. 
15 Korte SM, de Boer SF, de Kloet ER, Bohus B. Anxiolytic-like effects of selective mineralocorticoid and glucocorticoid antagonists on fearenhanced behavior in the elevated plus-maze. Psychoneuroendocrinology 1995; 20: 385-394.

16 Korte SM, Korte-Bouws GA, Koob GF, De Kloet ER, Bohus B. Mineralocorticoid and glucocorticoid receptor antagonists in animal models of anxiety. Pharmacol, Biochem Behav 1996; 54: 261-267.

17 Young EA, Akana S, Dallman MF. Decreased sensitivity to glucocorticoid fast feedback in chronically stressed rats. Neuroendocrinology 1990; 51: $536-542$.

18 Young EA. Normal glucocorticoid fast feedback following chronic 50\% corticosterone pellet treatment. Psychoneuroendocrinol 1995; 20: 771-784.

19 Liberzon I, Krstov M, Young EA. Stress-restress: effects on ACTH and fast feedback. Psychoneuroendocrinology 1997; 22: 443-453.

20 Herman JP, Schafer MKH, Young EA, Thompson R, Douglass J, Akil $\mathrm{H}$, Watson SJ. Evidence for hippocampal regulation of neuroendocrine neurons of the hypothalamo-oituitary-adrenocortical axis. J Neurosci 1989; 9: 3072-3082.

21 Reul JM, Probst JC, Skutella T, Hirschmann M, Stec IS, Montkowski A, Landgraf R, Holsboer F. Increased stress-induced adrenocorticotropin response after long-term intracerebroventricular treatment of rats with antisense mineralocorticoid receptor oligodeoxynucleotides. Neuroendocrinology 1997; 65: 189-199.

22 van Dijken HH, de Goeij DC, Sutanto W, Mos J, de Kloet ER, Tilders FJ. Short inescapable stress produces long-lasting changes in the brainpituitary-adrenal axis of adult male rats. Neuroendocrinology 1993; 58: $57-64$.

23 Oitzl MS, Fluttert M, de Kloet ER. The effect of corticosterone on reactivity to spatial novelty is mediated by central mineralocorticosteroid receptors. European J Neuroscience 1994; 6: 1072-1079.

24 Joels M, de Kloet ER. Mineralocorticoid and glucocorticoid receptors in the brain. Implications for ion permeability and transmitter systems. Prog Neurobiol 1994; 43: 1-36.

25 Pavlides C, Ogawa S, Kimura A, McEwen BS. Role of adrenal steroid mineralocorticoid and glucocorticoid receptors in long-term potentiation in the CA1 field of hippocampal slices. Brain Res 1996; 738: 229-235.

26 Antelman SM. Time-dependent sensitization as the cornerstone for a new approach to pharmacotherapy:drugs as foreign/stressful stimuli. Drug Develop Res 1988; 14: 1-30.
27 Antelman SM, Knopf S, Kocan D, Edwards DJ, Ritchie JC, Nemeroff CB. One stressful event blocks multiple actions of diazepam for up to at least a month. Brain Res 1988; 445: 380-385.

28 van Dijken HH, Mos J, van der Heyden JA, Tilders FJ. Characterization of stress-induced long-term behavioural changes in rats: evidence in favor of anxiety. Physiol Behav 1992; 52: 945-951.

29 Van Dijken HH, Tilders FJ, Olivier B, Mos J. Effects of anxiolytic and antidepressant drugs on long-lasting behavioural deficits resulting from one short stress experience in male rats. Psychopharmacol (Berl) 1992; 109: 395-402.

30 Pitman DL, Ottenweller JE, Natelson BH. Effect of stressor intensity on habituation and sensitization of glucocorticoid responses in rats. Behav Neuroscience 1990; 104: 28-36.

31 Spencer RL, Young EA, Choo PH, McEwen BS. Adrenal steroid type I and type II receptor binding: estimates of in vivo receptor number, occupancy, and activation with varying level of steroid. Brain Res 1990; 514: $37-48$

32 Bremner JD, Randall P, Scott TM, Bronen RA, Seibyl JP, Southwick SM, Delaney RC, McCarthy G, Charney DS, Innis RB. MRI-based measurement of hippocampal volume in patients with combat-related post-traumatic stress disorder. Am J Psychiatry 1995; 152: 973-981.

33 Gurvits TV, Shenton ME, Hokama H, Ohta H, Lasko NB, Gilbertson MW, Orr SP, Kikinis R, Jolesz FA, McCarley RW, Pitman RK. Magnetic resonance imaging study of hippocampal volume in chronic, combatrelated posttraumatic stress disorder. Biol Psychiatry 1996; 40: 1091-1099.

34 de Kloet ER, Sutanto W, van den Berg DT, Carey MP, van Haarst AD, Hornsby CD, Meijer OC, Rots NY, Oitzl MS. Brain mineralocorticoid receptor diversity: functional implications. J Steroid Biochem Mol Biol 1993; 47: 183-190.

35 Patel PD, Sherman TG, Goldman DJ, Watson SJ. Molecular cloning off a mineralocorticoid receptor of cDNA from rat hippocampus. Mol Endocrinol 1989; 3: 1877-1885.

36 Lopez JF, Vazquez DM, Akil H, Watson SJ. Effect of imipramine administration and swim stress on the hypothalamic pituitary adrenal axis. Endocrine 1994; 2: 723-728.

37 Paxinos G, Watson C. the Rat Brain in Stereotaxic Coordinates. Orlando, FL: Academic, 1986. 